Disclosure of Interests: Piotr Ligocki Consultant for: Accord Healthcare, Grzegorz Orlik Employee of: Accord Healthcare, Vishal Vekariya Employee of: Intas Pharmaceuticals

DOI: 10.1136/annrheumdis-2019-eular.1948

\section{THU0180 INFLUENCE OF BLUE MUSSEL (MYTILUS EDULIS) INTAKE ON FATTY ACID COMPOSITION IN ERYTHROCYTES AND PLASMA PHOSPHOLIPIDS AND SERUM METABOLITES IN WOMEN WITH RHEUMATOID ARTHRITIS}

Helen Lindqvist ${ }^{1}$, Inger Gjertsson ${ }^{1}$, Philip Calder ${ }^{2}$, Linnea Barebring ${ }^{1} .{ }^{1}$ University of Gothenburg, Medicine, Gothenburg, Sweden; ${ }^{2}$ University of Southampton, Southampton, United Kingdom

Background: The positive effects of omega-3 on risk of cardiovascular disease, on inflammation and immune function are well established [1] Unfortunately fish as a source of omega-3 is not economically or environmentally sustainable. In contrast, blue mussel farming is beneficial for the environment since excessive nitrogen is removed at harvest and eutrophication of the sea is reduced [2]. Blue mussels contain not only omega-3, but are rich in nutrients such as zinc, selenium, riboflavin and carotenoids. We have previously shown, in the randomized cross-over trial Mussels, Inflammation and RA (MIRA), that disease activity (DAS28-CRP), fatigue, pain and general health in RA is improved by a dietary intervention with blue mussels compared to control [3]. It is not clear what the mechanisms of the intervention were, and if the intake of omega-3 from the blue mussels plays a role.

Objectives: The aim of this study was to investigate if the intake of blue mussels in patients with RA lead to changes in fatty acid composition in plasma phospholipids and erythrocytes and/or in metabolites (detected by NMR-metabolomics), compared to a control diet, in an attempt to understand the health beneficial effects found in the MIRA study.

Methods: Twenty-three women completed the randomized $2 \times 11$-week cross-over dietary intervention, exchanging one cooked meal a day, five days a week, with a meal including $75 \mathrm{~g}$ blue mussels or $75 \mathrm{~g}$ meat. Fatty acid composition in erythrocytes and plasma and ${ }^{1} \mathrm{H}$-NMR metabolomics data were analysed and multivariate data analysis; Orthogonal Projections to Latent Structures with Discriminant Analysis (OPLS-DA) and OPLS with effect projections (OPLS-EP)) were performed to compare the two diets.

Results: Intake of the blue mussels led to a different fatty acid profile in erythrocytes, compared to control, and all samples could be correctly classified with OPLS-DA (figure 1). The changes included significant increases in omega-3 fatty acids eicosapentaenoic acid (EPA) and docosahexaenoic acid (DHA). The patterns for plasma phospholipids and ${ }^{1} \mathrm{H}$ NMR serum metabolites were not as specific for the diets and metabolites were strongly influenced by body mass index (BMI) (figure 2).
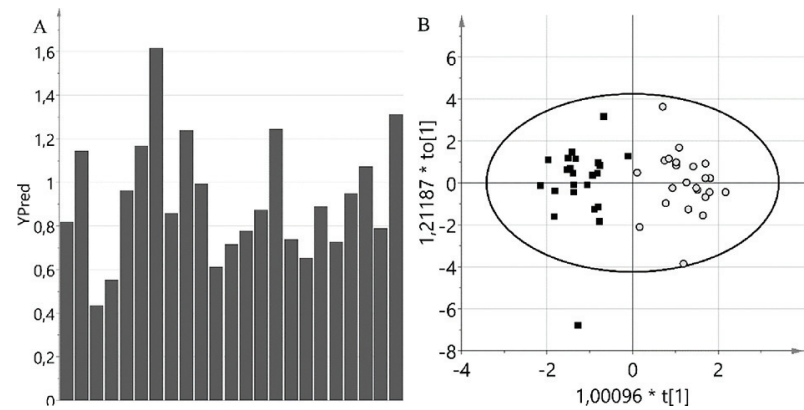

Abstract THU0180 - Figure 1. A) Model prediction for all individuals in OPLS-EP models for erythrocyte fatty acids (\%) B) OPLS-DA models showing separation for erythrocyte fatty acids $(\%$, Black boxes $=$ control diet, grey circles $=$ blue mussel diet

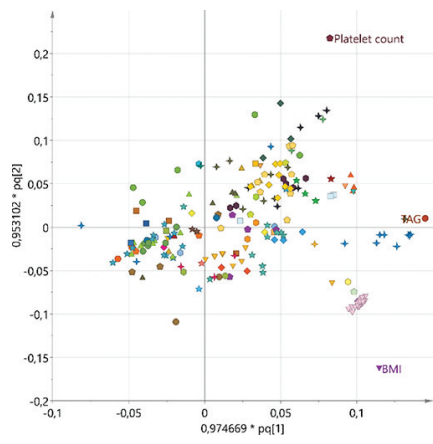

Abstract THU0180 - Figure 2. Orthogonal Projections to Latent Structures (OPLS) for metabolites in relation to significant related factors $(n=92)$. TAG $=$ triacylglycerides, $B M I=$ body mass index

Conclusion: To conclude, the change in fatty acid pattern in erythrocytes could be related to reduction in disease activity in the MIRA-study, although it cannot be excluded that other factors than omega- 3 fatty acids potentiate the effect. Multivariate modelling of fatty acids in erythrocytes increased the precision for compliance, compared to evaluating EPA and DHA content alone.

\section{REFERENCES:}

[1] Calder PC. Marine omega-3 fatty acids and inflammatory processes: Effects, mechanisms and clinical relevance. Biochim Biophys Acta. 2015;1851:469-84. doi: 10.1016/j.bbalip.2014.08.010. Epub Aug 20.

[2] Lindahl O, Hart R, Hernroth B, Kollberg S, Loo LO, Olrog L, et al. Improving marine water quality by mussel farming: a profitable solution for Swedish society. Ambio. 2005;34:131-8.

[3] Lindqvist HM, Gjertsson I, Eneljung T, Winkvist A. Influence of Blue Mussel (Mytilus edulis) Intake on Disease Activity in Female Patients with Rheumatoid Arthritis: The MIRA Randomized Cross-Over Dietary Intervention. Nutrients. 2018;10(4).nu10040481. doi: 10.3390/nu.

Disclosure of Interests: Helen Lindqvist Employee of: Yes, for JanssenCilag $A B$ in 2001-2003, Before I was a phD-student and within a different field (dementia). My research field is within diet and Rheumatology., Inger Gjertsson: None declared, Philip Calder: None declared, Linnea Barebring: None declared

DOI: 10.1136/annrheumdis-2019-eular.3009

\section{THU0181 TREATMENT WITH UPADACITINIB RESULTS IN THE NORMALIZATION OF KEY PATHOBIOLOGIC PATHWAYS IN PATIENTS WITH RHEUMATOID ARTHRITIS: BIOMARKER RESULTS FROM THE PHASE 3 SELECT- NEXT AND SELECT-BEYOND STUDIES}

Thierry Sornasse ${ }^{1}$, Jeremy Sokolove ${ }^{1}$, lain McInnes ${ }^{2} .{ }^{1}$ AbbVie Immunology Clinical Development, Redwood City, United States of America; ${ }^{2}$ University of Glasgow, Glasgow, United Kingdom

Background: Upadacitinib (UPA), an oral JAK inhibitor selective for JAK1, demonstrated efficacy in patients with moderate-to-severe rheumatoid arthritis (RA) with an inadequate response (IR) to conventional synthetic disease-modifying anti-rheumatic drugs (csDMARDs) or biologic DMARDs (bDMARDs) in the SELECT-NEXT ${ }^{1}$ and SELECT-BEYOND ${ }^{2}$ trials, respectively. The pivotal immune regulatory pathway targets served by JAK1 in patients have not been comprehensively explored.

Objectives: To investigate the mode of action (MoA) of UPA in patients with RA via a proteomic approach that evaluates a set of plasma proteins associated with inflammation.

Methods: Patients from the SELECT-NEXT and SELECT-BEYOND (PBO, $\mathrm{n}=167$; UPA $15 \mathrm{mg} Q D, \mathrm{n}=200$ ) studies were randomly selected from the pool of patients with plasma samples available at baseline, Week 2, and Week 12. Samples from 24 age- and sex-matched healthy controls were included. The levels of 92 proteins were analyzed using the Olink ${ }^{\circledR}$ Inflammation Panel. Results from both studies were combined. Data were clustered using the Ward (unsupervised) method; correlations were calculated using the Pearson method; and multiple comparisons were corrected using the Benjamini-Hochberg method; all statistical analyses were performed in JMP 13.10 (SAS Institute). Pathway analysis was performed with Ingenuity ${ }^{\circledR}$ Pathway Analysis (Qiagen Inc.) version 45868156 . 
Results: At baseline, levels of IL-6, CXCL9, CXCL10, and CCL7 correlated significantly with baseline DAS28-ESR, consistent with effector roles for IL-6 and interferon (IFN) in intercurrent disease activity. Clustering of the differential protein fold change at Weeks 2 and 12 for UPA and PBO groups revealed four clusters enriched for proteins related to: 1) IL6 , IFN, leukocyte trafficking, and macrophage activation $(\downarrow \downarrow \downarrow)$; 2) $T$ helper cell differentiation $(\downarrow)$; 3) T and B cell signaling $(\downarrow \downarrow)$; and 4) hematopoiesis and myeloid cell differentiation ( $\uparrow)$. Pathway analysis based on the differential expression of 37 significantly modulated proteins suggests that treatment with UPA results in the normalization of key pathways associated with the pathobiology of RA including: 1) pathways associated with IL-1, IL-6, IL-12, IL-15, IL-18, IFN $\alpha$, IFN $\beta$, IFN $\gamma$, CSF2, and TNF; and 2) pathways associated with behaviors of leukocytes (lymphocytes, myeloid cells, and granulocytes), including leukocyte migration, $\mathrm{T}$ cell response, and inflammatory response. In keeping with the latter, the changes in IL6, CCL23, CCL7, MMP1, and S100A12 levels at Week 12 correlated significantly with the relative change in DAS28-ESR, suggesting a link between UPA MoA and macrophage activation.

Conclusion: In keeping with its selectivity for JAK1, UPA operates via inhibition of multiple JAK1-dependent upstream pathways that result in the normalization of key functional downstream effects associated with the pathobiology of RA, including $T$ cell and myeloid cell-related pathways. Notably, non-JAK signaling pathways also normalize, suggesting functional integration of JAK1 with parallel pathogenic signaling in RA effector cells.

\section{REFERENCES :}

[1] Burmester GR, et al. Lancet 2018;391:2503-12;

[2] Genovese MC, et al. Lancet 2018;391:2513-24

Acknowledgement: AbbVie, Inc was the study sponsor, contributed to the study design, data collection, analysis \& interpretation, and to writing, reviewing, and approval of the final version. Medical writing support was provided by John Ewbank, PhD, of 2 the Nth.

Disclosure of Interests: Thierry Sornasse Shareholder of: AbbVie, Employee of: AbbVie, Jeremy Sokolove Shareholder of: AbbVie, Employee of: AbbVie, lain Mclnnes Grant/research support from: AstraZeneca, Celgene, Compugen, Novartis, Roche, UCB Pharma, Consultant for: AbbVie, Celgene, Galvani, Lilly, Novartis, Pfizer, UCB Pharma

DOI: 10.1136/annrheumdis-2019-eular.2994

\section{THU0182 PHARMACOKINETICS AND SAFETY OF A SINGLE ORAL DOSE OF PEFICITINIB (ASP015K) IN SUBJECTS WITH NORMAL AND IMPAIRED RENAL FUNCTION}

Daisuke Miyatake $^{1}$, Tomohisa Shibata $^{1}$, Mai Shibata ${ }^{1}$, Yuichiro Kaneko $^{1}$, Kazuo Oda ${ }^{2}$, Tetsuya Nishimura ${ }^{1}$, Masataka Katashima ${ }^{1}$, Hisakuni Sekino ${ }^{3}$, Kenichi Furihata ${ }^{4}$, Akinori Urae ${ }^{5}$. ${ }^{1}$ Astellas Pharma, Inc., Tokyo, Japan; ${ }^{2}$ Astellas Research Institute of America LLC, Northbrook, United States of America; ${ }^{3}$ Houeikai Medical Corporation, Sekino Clinical Pharmacology Clinic, Tokyo, Japan; ${ }^{4}$ P-One Clinic, Keikokai Medical Corporation, Tokyo, Japan; ${ }^{5}$ Mediscience Planning Inc., Tokyo, Japan

Background: Peficitinib (ASP015K), a novel oral Janus kinase inhibitor, was shown to be efficacious as once-daily therapy for moderate-to-severe rheumatoid arthritis (RA) in a phase $2 \mathrm{~b}$ study (NCT01649999) ${ }^{1}$ and in two phase 3 studies (NCT02308163 ${ }^{2}$ and NCT02305849). ${ }^{3}$ Mean urinary excretion of peficitinib accounted for $9-15 \%$ of the oral dose. ${ }^{4}$

Objectives: To assess the pharmacokinetics (PK) and safety of a single, oral dose of peficitinib $150 \mathrm{mg}$ in subjects with normal and impaired renal function.

Methods: This was an open-label, single-dose, parallel-group study conducted at two centres in Japan. All subjects were aged 20-75 years with a body mass index $\geq 17.6$ to $<30.0 \mathrm{~kg} / \mathrm{m}^{2}$. Renal function was classified according to estimated glomerular filtration rate (eGFR) using a GFR predictive equation for Japanese subjects: normal $>90 \mathrm{~mL} / \mathrm{min} / 1.73$ $\mathrm{m}^{2}$; mild impairment $\geq 60$ to $<90 \mathrm{~mL} / \mathrm{min} / 1.73 \mathrm{~m}^{2}$; moderate impairment $\geq 30$ to $<60 \mathrm{~mL} / \mathrm{min} / 1.73 \mathrm{~m}^{2}$; and severe impairment $\geq 15$ to $<30 \mathrm{~mL} / \mathrm{min} /$ $1.73 \mathrm{~m}^{2}$. Subjects with impaired renal function had unchanged renal impairment treatment (including diet) within 14 days prior to dosing. Subjects received a single, oral dose of peficitinib $150 \mathrm{mg}$ tablet under fasting conditions in a hospital setting. The selected dose was based on the peficitinib daily dose in the phase 3 RA studies. Blood samples for peficitinib plasma PK analysis were collected before administration and up to $72 \mathrm{~h}$ post dose. Safety was assessed throughout the study.

Results: A total of 31 subjects $(87.1 \%$ male; Table 1$)$ were enrolled and received study drug according to study protocol. Subjects comprised 8 with normal renal function, and 8 with mild, 8 with moderate and 7 with severe renal impairment. The peficitinib concentration-time profiles from dosing to $72 \mathrm{~h}$ (Fig. 1), extrapolated to infinity $\left(A \cup C_{\text {inf }}\right)$ and maximum concentration $\left(\mathrm{C}_{\max }\right)$ were similar between those with normal and impaired renal function (Table 2). Two subjects had mild/grade 1 (CTCAE v4.0 $\mathrm{JCOG}$ ) treatment-emergent adverse events (TEAEs): $1 / 8$ (12.5\%) with nor mal renal function had a headache (considered to be drug-related) and $1 / 8(12.5 \%)$ with mild renal impairment had increased alanine aminotransferase (ALT) (not considered to be drug-related). There were no serious TEAEs or deaths during the study. There were no clinically significant mean changes from baseline in other clinical laboratory parameters or vital sign measurements, except for grade 1 increased ALT in a subject with mild renal impairment.

Abstract THU0182 -Table 1

Table 1 Demographic characteristics (PKAS)

\begin{tabular}{|c|c|c|c|c|c|}
\hline \multirow[b]{2}{*}{ Parameter } & \multicolumn{4}{|c|}{ Renal function ${ }^{1}$} & \multirow[b]{2}{*}{ Total } \\
\hline & Normal (n=8) & $\begin{array}{l}\text { Mild } \\
\text { impairment } \\
(n=8)\end{array}$ & \begin{tabular}{|l} 
Moderate \\
impairment \\
$(n=8)$
\end{tabular} & \begin{tabular}{|l} 
Severe \\
impairment \\
$(n=7)^{2}$
\end{tabular} & \\
\hline \begin{tabular}{|l} 
Male, $n(\%)$ \\
\end{tabular} & $6(75.0)$ & $7(87.5)$ & $7(87.5)$ & $7(100.0)$ & $27(87.1)$ \\
\hline $\begin{array}{l}\text { Median (min, } \\
\text { max) age, } y\end{array}$ & $56.5(23,69)$ & $59.5(37,70)$ & $62.0(46,75)$ & $67.0(58,71)$ & $60.0(23,75)$ \\
\hline \begin{tabular}{|l|} 
Median (min, \\
max) weight, kg
\end{tabular} & \begin{tabular}{|l|}
$65.8(55.5$, \\
$73.0)$ \\
\end{tabular} & \begin{tabular}{|l|}
$66.8(46.7$ \\
$72.6)$ \\
\end{tabular} & \begin{tabular}{|l|}
$66.4(56.5$, \\
$76.4)$ \\
\end{tabular} & \begin{tabular}{|l|}
$69.4(62.9$, \\
$77.5)$ \\
\end{tabular} & \begin{tabular}{|l|}
67.6 (46.7) \\
$77.5)$ \\
\end{tabular} \\
\hline $\begin{array}{l}\text { Median (min, } \\
\text { max) BMI, } \mathrm{kg} / \mathrm{m}^{2}\end{array}$ & \begin{tabular}{|l}
23.4 (20.9, \\
$28.3)$
\end{tabular} & $\begin{array}{l}23.0 \text { (18.6, } \\
24.7)\end{array}$ & \begin{tabular}{|l}
$23.6(22.3$, \\
$28.0)$
\end{tabular} & \begin{tabular}{|l}
$25.0(23.2$, \\
$29.0)$
\end{tabular} & \begin{tabular}{|l}
$23.6(18.6$, \\
$29.0)$
\end{tabular} \\
\hline $\begin{array}{l}\text { Median }(\min , \\
\mathrm{max} \text { ) eGFR, } \\
\mathrm{mL} / \mathrm{min} / 1.73 \mathrm{~m}^{2}\end{array}$ & \begin{tabular}{|l}
$94.4(91.7$ \\
$104.4)$
\end{tabular} & \begin{tabular}{|l}
$79.8(66.7$ \\
$83.4)$
\end{tabular} & \begin{tabular}{|l}
$48.2(37.0$, \\
$58.8)$
\end{tabular} & $\begin{array}{l}23.5 \text { (18.0, } \\
27.3)\end{array}$ & $\begin{array}{l}66.7(18.0 \\
104.4)\end{array}$ \\
\hline
\end{tabular}

Classification of renal impairment was based on the predictive glomerular filtration rate equation: for males, eGFR cuen $\left(\mathrm{mL} / \mathrm{min} / 1.73 \mathrm{~m}^{2}\right)=194 \times$ (serum creatinine [mg/d d ] - $1.094 \times$ (age)-0.287; and for females, (male eGFR) $\times 0.739$. Definitio were: normat function $290 \mathrm{~mL} / \mathrm{min} / 1.73 \mathrm{~m}^{2}$. mild impairment 260 to $<90 \mathrm{~mL} / \mathrm{min} / 1.73 \mathrm{~m}^{2}$. moderate impairment 230 $<60 \mathrm{~mL} / \mathrm{min} / 1.73 \mathrm{~m}^{2}$; and severe impairment 215 to $<30 \mathrm{~mL} / \mathrm{min} / 1.73 \mathrm{~m}^{2}$

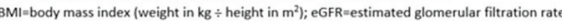

Conclusion: Exposure after a single $150 \mathrm{mg}$ oral dose of peficitinib under fasting conditions was similar between subjects with and without renal impairment. The peficitinib dose was generally well tolerated, with no differences in TEAE incidence by renal function.

Abstract THU0182 -Table 2

Table 2 Plasma PK parameters of peficitinib (PKAS)

\begin{tabular}{|c|c|c|c|c|}
\hline \multirow[b]{2}{*}{ Parameter } & \multicolumn{4}{|c|}{ Renal function ${ }^{1}$} \\
\hline & Normal $(n=8)$ & $\begin{array}{l}\text { Mild impairment } \\
(n=8)\end{array}$ & $\begin{array}{l}\text { Moderate } \\
\text { impairment } \\
(n=8)\end{array}$ & $\begin{array}{l}\text { Severe } \\
\text { impairment } \\
(n=7)^{2}\end{array}$ \\
\hline $\begin{array}{l}\text { Mean (SD) AUC inf, } \\
\text { ng.h } / \mathrm{mL}\end{array}$ & $1595(360.2)$ & $1419(385.0)$ & $1427(562.7)$ & 1933 (984.6) \\
\hline $\begin{array}{l}\text { GMR }(90 \% \mathrm{CI}) \text { for } \\
\text { AUC inf vs normal } \\
\text { renal function }\end{array}$ & - & $0.87(0.61,1.25)$ & $0.83(0.58,1.19)$ & $1.09(0.74,1.60)$ \\
\hline $\begin{array}{l}\text { Mean (SD) } \mathrm{C}_{\max } \\
\mathrm{ng} / \mathrm{mL}\end{array}$ & $426.4(156.8)$ & 376.7 (119.6) & 342.1 (134.9) & $387.2(260.4)$ \\
\hline $\begin{array}{l}\text { GMR }(90 \% \mathrm{Cl}) \text { for } \\
\mathrm{C}_{\max } \text { Vs normal } \\
\text { renal function }\end{array}$ & - & $0.90(0.60,1.35)$ & $0.78(0.52,1.18)$ & $0.78(0.51,1.20)$ \\
\hline Mean (SD) $t_{1 / 2,} h$ & $6.80(4.34)$ & $14.96(8.33)$ & $14.36(14.33)$ & $10.80(5.13)$ \\
\hline
\end{tabular}

'Classification of renal impairment was based on the predictive glomerular filtration rate equation: for males, eGFRecerk $\left(\mathrm{mL} / \mathrm{min} / 1.73 \mathrm{~m}^{2}\right)=194 \times($ serum creatinine $[\mathrm{mg} / \mathrm{dL}])-1.094 \times$ (age)-0.287; and for females, (male eGFR) $\times 0.739$. Definition were: normal function $290 \mathrm{~mL} / \mathrm{min} / 1.73 \mathrm{~m}^{2}$; mild impairment 260 to $<90 \mathrm{~mL} / \mathrm{min} / 1.73 \mathrm{~m}^{2}$; moderate impairment 230 to $60 \mathrm{~mL} / \mathrm{min} / 1.73 \mathrm{~m}^{2}$; and severe impairment 215 to $<30 \mathrm{~mL} / \mathrm{min} / 1.73 \mathrm{~m}^{2}$.

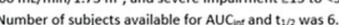

AUC carea under the concentration-time curve from the time of dosing extrapolated to infinity; $\mathrm{Cl}=$ confidence intervat;

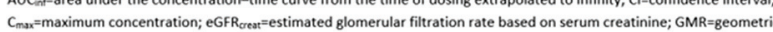

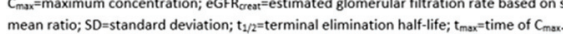

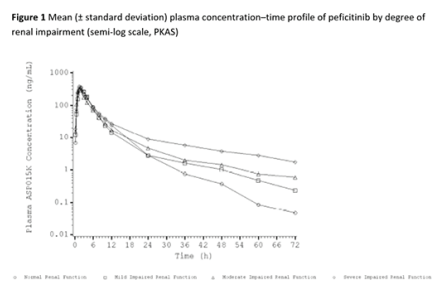

Abstract THU0182 - Figure 1

\section{REFERENCES}

[1] Takeuchi T, et al. Ann Rheum Dis 2016; 75: 1057-64; 2. Tanaka Y, et al. ACR/ARHP Annual Meeting 2018: Abstract 887; 3. Takeuchi T, et al. ACR/ARHP Annual Meeting 2018: Abstract 888; 4. Cao YJ, et al. Clin Pharmacol Drug Dev 2016;5:435-49 